$$
\begin{array}{r}
\text { Submitted Adu. span hPis } \\
10 / 00 \\
546773
\end{array}
$$

\title{
Ionospheric Flow and Escape of Ions from Titan and Venus
}

\author{
R. E. Hartle', D. S. Intriligator', and J. M. Grebowsky' \\ ${ }^{\prime}$ NASA Goddard Space Flight Center, Greenbelt, MD 20771, USA \\ ${ }^{2}$ Carmel Research Center, Santo Monica CA 90406 USA
}

\begin{abstract}
Knowledge gained from measurements and models is used to study the high-speed plasmas interacting with the atmospheres and ionospheres of Titan and Venus. Considering the similarities of the interactions, comparative analysis is used to support the interpretations of observations made at each body. Ionospheric flow inferted to exist by analysis of measurements made from the Pioneer Venus Orbiter supports the interpretation of similar flow in the ionosphere of Titan. The concept that cold ions escape from the ionosphere of Venus is supported by the Voyager 1 observation that cold ions escape down the magnetic tail of Titan. Pickup $\mathrm{O}^{+}$ion energy distributions observed at their source in the ionosheath of Venus are shown to be influenced by finite gyroradius effects. The signatures of such effects are expected to be retained as the ions move into the wakes of Titan and Veaus.
\end{abstract}

\section{NTRODUCTION}

A considerable fraction of atmospheric loss at Venus and Titan is in the form of plasma escape. This is due in part to the fact that the ionospheres of these unmagnetized bodies interact directly with the high-speed plasmas flowing around them. We use the similarities of the interactions to reinforce both our earlier and preseat interpretations of measurements made at each body from different measurement sites and instruments. In particular, the implications of ion measurernents made by the Plasma Science Instrument (PSD) on Voyager I as it Ilew through the ionotail of Titan are related to those of the jon measurements in the ionosphere, ionosheath, and distant ionotail of Venus. The latter measurements were made by the Orbiter Ion Mass Spectrometer (ODMS) and the Orbiter Plasma Analyzer (OPA) onboard the Pjoneer Venus Orbiter (PVO). These measurenents are used to reinforce the concept that some of the "cool" jons of jonospheric origin escape down the ionotails of each body. Further support of this picture comes from measurements by the CELLAS CTOF instrument onboard SOHO, where observations of "cool" ions in the absence of "bot" pickup jons were made in Venus' wake at ? AU. An analysis of pickup $\mathrm{O}^{+}$ion observations by the OPA in the scurce and wake regions of Venus demonstrates the importance of finite gyroradius effects on the velocity distributions. This result supports the interpretation of finite gyroradius effects on the PSI measurements of heavy pickup ions at Titan.

\section{TITAN}

The PSI onboard Voyager 1 made ion measurements as it flew by Titan on its way through the magnetosphere of Saturn (Bridge et al., 1981). The plasma science instrument had four Faraday cups, three of which were pointing sunward and the forth, the D cup, pointed approximately towards the corotational direction of Saturn's magnetospheric plasma. During the flyby, magnetometer measurements indicated that Titan essentially possesses no intrinsic magnetic feld (Ness et al., 1981). Saturn's rotating magnetospheric plasma was found to interact directly with Titan's atcosphere and ionosphere and produced a magnetic tail in its wake, similar to the solar wind interaction observed at Venus. As Voyager 1 approached Titan, pickup $H$ ions were identified (Hartle et al., 1982), just outside the magnetic tail, by the sudden $\mathrm{H}$ flux dropout above their cutoff energy, which is 2 times the plasma speed times the sine of the angle between the magnetic field and the plasma velocity. As the spacecraft flow through the magnetic tail of Titan, only the D cup observed ion fluxes (Figure 1), signifying that the plasma 
was flowing away from Titan (note that the sloped, straight lines in the figure are the noise levels of the PSI). The best-Et analysis of these spectra indicated an ion density of $-10 \mathrm{~cm}^{-3}$, flow speed of $-4 \mathrm{~km} \mathrm{~s} \mathrm{~s}^{-1}$ and a temperature of 1-2 ev, which is much cooler than the plasma outside Titan's tgil. All of the above features led to the speculation that these "cold", escaping ions were of ionospheric origin (Hartle et al., 1982). The most likely mass of these escaping ions was 28 amu, the mass of the ion thought to be the dominant topside ion in the ionosphere at that time; i.e., $\mathrm{H}_{2} \mathrm{CN}^{+}$.

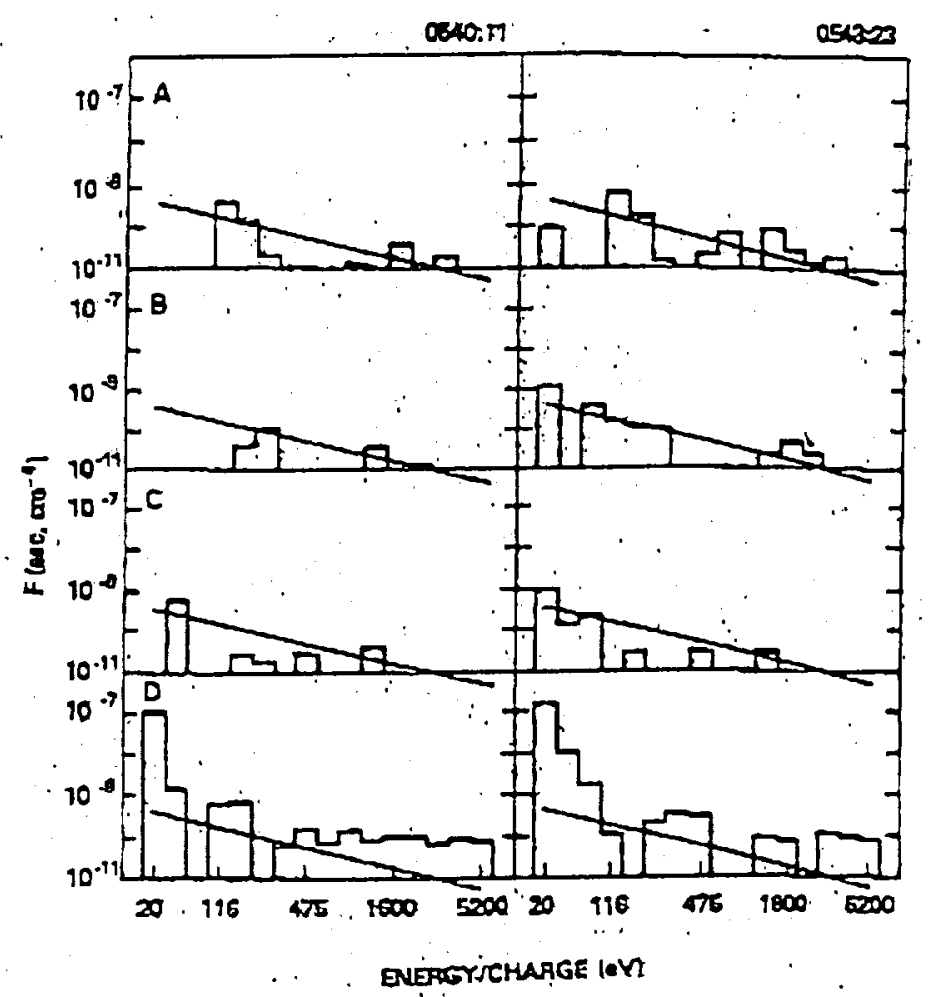

Fig. 1. Flux measurements in A, B, C and D cups of the PSI at 2 points in the magnetic tail of Titan. The A, B, and $C$ cups point sunward while the D cup points into the flow of Saturn's rotaing magnetospheric plasma.

These measurements caused us to think that if the escaping ions are of ionospheric origin, then there should be signatures of such upward flow in Titan's jonosphere. Confirmation of this idea will bave to wait at least until the Cassini mission. In the interim, we have applied the idea to the ionosphere of Venus, where in-situ measurements were made in the ionosphere of Venus during the PVO mission.

\section{VENUS}

Ions can escape from a number of places at Venus; e.g., pickup ions born above the ionopause, ions flowing upward from the nightside ionosphere, and those flowing from the dayside ionosphere to the mightside, where a faction escape from the planet. The in-situ measurements of ion composition, densities and temperatures in the ionosphere and pickup ions in the ionosheatb during the PVO mission provide the opportunity to look for signatures of such ion escape at their sources.

\section{Day to Night Flow}

Day to right transport of $\mathrm{O}^{+}$bas been known for some time to be essential in maintaining observed levels of $\mathrm{O}_{2}{ }^{+}$and $\mathrm{O}^{+}$in the nightside (sce review, Brace et al., 1995). Such a process entails both verical and horizontal ion flow in the dayside ion source region. Vertical flow is treated in the following while the horizontal flow has been analyzed extensively by Krudsen et al. (1982). Vertical ion flow was not measured directly in the ionosphere

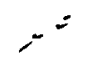


of Venus by instruments on the PVO mission. However, an ion flow algorithm has been developed to extract vertical ion speeds from PVO measurements (Hartle and Grebowsky, 1993). The algorithm is dependent on ion and electron densities, temperatures, and their gradients measured by the ODMS, the Orbiter Electron Temperature Probe (OETP) and the Orbiter Retarding Potential Analyzer (ORPA). Also used are the magnetic field measurements of the Orbiter Magnetometer (OMAG). This technique was first used in the nightside ionosphere to obtain vertical ion wind speeds of $\mathrm{H}^{+}$and $\mathrm{D}^{+}$, from which a strong polarization electric field was shown to be the principal force accelerating the ions upward (Hartle and Grebowsky, 1995). This process has proved to be 3 major escape flux for bydrogen and deuterium, contributing significantly to the loss and evolution of water on Venus (Hartle et al., 1996).

The algorithm can also be applied to heavier constituents on the day and oight side ionospheres. The dayside ionosphere is known to exist in at least two dynamic states, compressed and extended. In the former, there is evidence that the solar wind ram pressure is high enough to cause the topside ionosphere to flow downward, resulting is a lower ionopause and a shorter scale height for the dominant ion, $O^{+}$(Bauer and Hartle, 1974). When the algorithm is applied to an extended ionosphere, typically occurring when the ionopause is higher than about 500 $\mathrm{km}$, upward flow is found. This is the case for orbit 418, where upward winds shows in Figure 2 are found for $\mathrm{O}^{+}$, $\mathrm{O}_{2}^{+}$, and $\mathrm{C}^{+}$. Note: the vertical winds were evaluated near the subsolar point so that the effects of horizontal winds on the calculation were minimized.) These profiles are typical of upward winds obtained when the dayside ionosphere is extended in the presence of low solar wind ram pressures. The dowaward flow of $\mathrm{O}^{+}$obtained from the highly compressed jonosphere of orbit 184 (ionopause below $300 \mathrm{~km}$ ) is contrasted in Figure 3 against the upward $\mathrm{O}^{+}$flow of arbit 418.

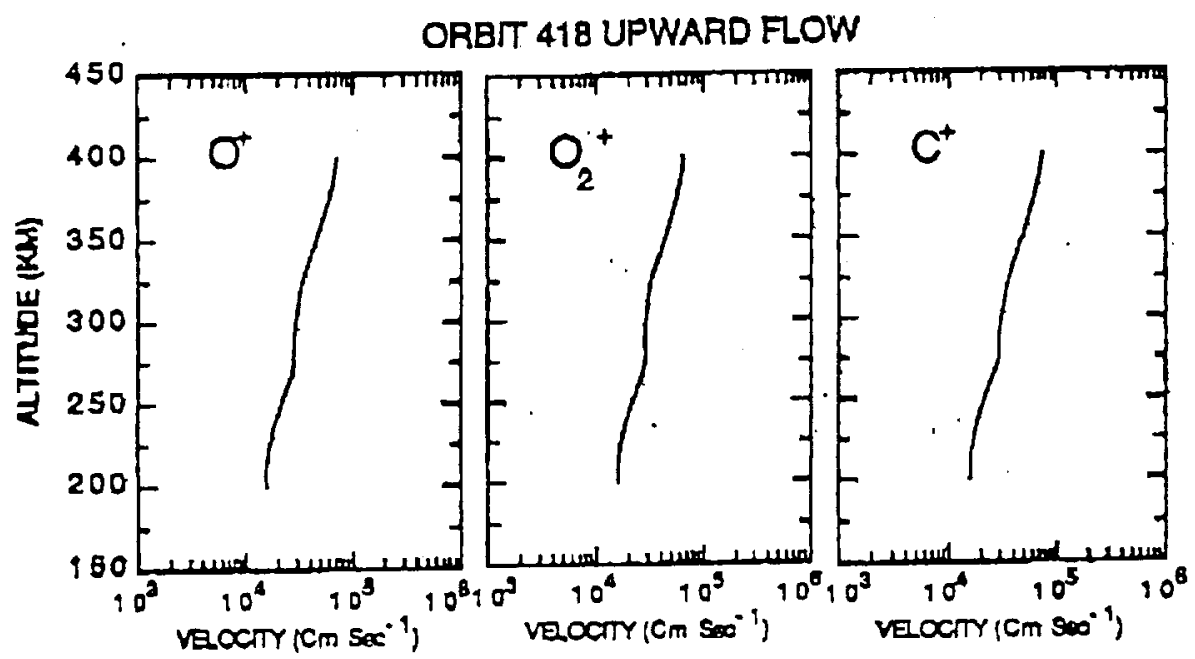

Fig 2. Upward tlow speeds of $\mathrm{O}^{+}, \mathrm{O}_{2}^{-}$and $\mathrm{C}^{+}$in dayside ionosphere of Venus near subsolar point.

When the analysis for the extended ionosphere is carried to altitudes higher than in Figure 2, the upward wind speed decreases due to an increase in the horizontal magnetic field intensity producing a downward magnetic pressure. This represents a qualitative tendency only, because the structured, strong vertical gradients of parameters in this region do not permit good quantitative values of ion wind speeds with the cursent data set. Nevertheless, it is clear that the ions slow down with increasing altitude while borizontal flow increases to conserve ion flux. Altogether, the deflection of upward flow toward the nightside by the magnetic barrier is consistent with a fountain-like flow field confined to the cavity below the ionopause suggested earlier by Cravens and Shinagawa (1991).

Considering this day to night flow picture, Brace et al., (1995) estimated that the dayside $\mathrm{O}^{+}$flux into the nighttime ionosphere, during times of uncompressed ionospheres, could considerably exceed the flux required to maintain the night $\mathrm{O}_{2}^{+}$layer. They suggested that the excess would escape as relatively cold plasma down the ionotail or as a cloud of plasma that bas broken away from the dayside ionopause region.

\section{Night Flow}


Esrlier, using this algorithon on the nightside, we obtained vertical ion wind speeds of $\mathrm{H}^{+}$and $\mathrm{D}^{+}$, from which a strong polarization electric field was shown to be the principal force accelerating the ions upward (Hartle and Grebowsky, 1995). This process has proved to be a major escape flux for bydrogen and deuterium, contributing significandly to the loss and evolution of water on Venus (Hartle et al., 1996). The upward flow of $H^{+}$and $D^{+}$ occurs in the prescnce of downward flowing $\mathrm{O}^{+}$, which maintain the nightside $\mathrm{O}_{2}^{+}$layer. However, when the algorithm is applied at altitudes well above the $\mathrm{O}_{2}^{+}$peak, we frequently find the flow reversals shown in Figure 4, where $\mathrm{O}^{+}$flows upward toward the ionotail. The profiles in this figure were generated from data in the midnight to 2:00 am sector that was averaged over Venus years 1,2 and 3. The altitude of the flow reversal is bighly sensitive to the spatial gradients. This is shown in Figure 3, where the range of altitudes is due to about a 10 percent variation in the $\mathrm{O}^{+}$scale height from its average observed value, which is used for the central reversal.

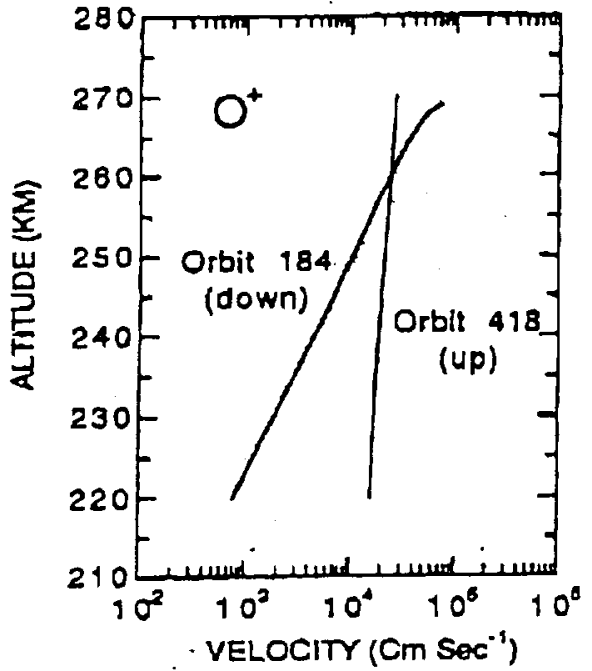

Fig 3. Downward subsolar region flow speed of $\mathrm{O}^{+}$for compressed ionosphere compared with upward speed for compressed ionosphere.

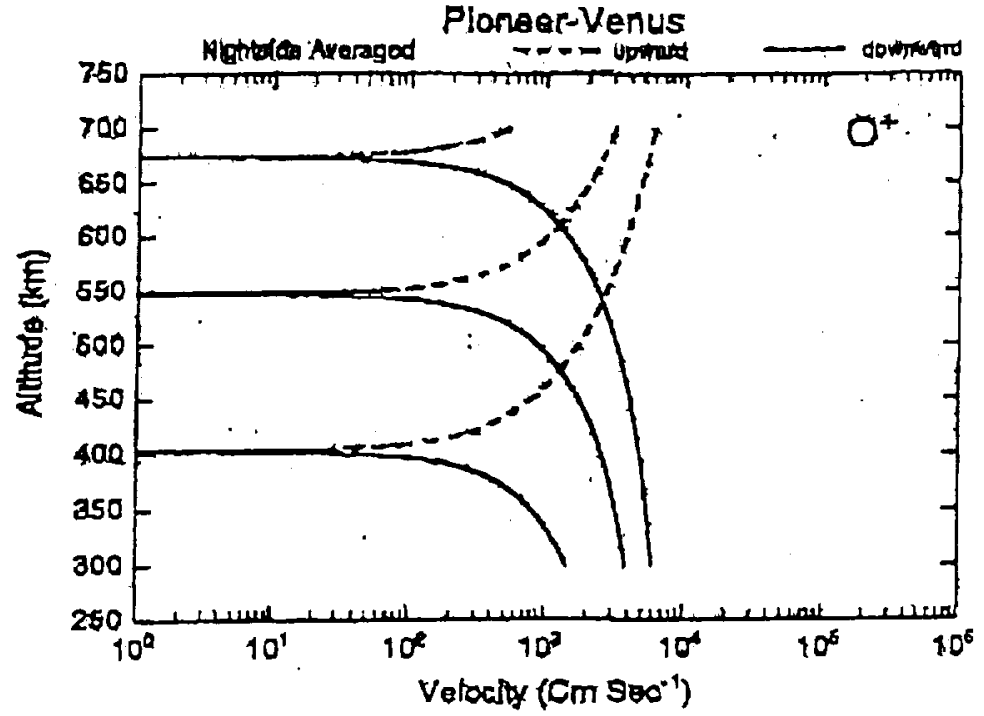

Fig 4. Upward and dowaward tlow speeds of $\mathrm{O}^{+}$ depicting flow jeversal in midnight sector of Venus'.

The day to night Dow of heavy ions like $0^{*}$, which can exceed the flow necessary to maintain the nightside ionosphere, coupled with the observed inference of upward flow of $\mathrm{O}^{+}$directly from the nightside ionosphere suggests the presence of a global ion flow pattern which includes the flow of ionospheric ions away from the nightside ionosphere into the ionotail of Veous. These "cold" ionospheric ions flowing into the ionotail are expected to be accelerated to solar wiod speeds by the motional electric field as the draped magnetic field straightens out and merges with the interplanetary field.

\section{Ionotail}

The possible presence of these cold escaping ions and/or pickup ions bave been sought using OPA measurements in the distant jonotail during PVO apospsis passes at about 12 Venus radii, $R_{v}$ (e.g., Inciligator, 1989; Slaven et al., 1989). Measureconents of $\mathrm{O}^{\prime}$ are possible when the plasma wind speed is low enough so that the beavy ions' energies are within the instrument's upper energy limit. The energy aridus of the $O^{+}$ions observed in the distant tail are much broader than those expected for the cold ions of ionospheric origin. Consequently, only pickup ions bave beeo identified on the apoapsis passes (Iotriligator, 1989; Slaven et al., 1989). However, the presence of cold jons could be inferred from those instances in the central region of the ionotail where there is complete absence of a plasma signal (Intriligatar, 1989). Although the pickup $\mathrm{O}^{+}$ions are "bot" relative to ionospheric ions, they have not becn observed to have measurable fluxes at the maximum possible pickup ion energy, which is $(1 / 2) 16 \mathrm{~m}_{p}\left(2 v_{p} \sin \alpha\right)^{2}$ or $64 \sin ^{2} \alpha$ ines the proton energy and an equivalent speed of $8 \sin \alpha$ times the proton bulk speed, where $m_{p}$ is the proton's mass, $v_{p}$ its bulk speed and $\alpha$ is the angle between the

$=\dot{2}$ 
plasma velocity and the magnetic field. The precise energy and speed is the result of where and how they were born, a point that is addressed below.

Although ionospheric jans were not observed in Venus' wake at $12 R_{v}$ by the OPA, $\mathrm{O}^{+}$and $\mathrm{C}^{+}$ions were Although moned at 1 AU by the CIOF detector of the CELIAS mass spectrometer instrument [Grunwaldt et al., 1997] on
SOHO. These measurements were made when SOHO passed through the predicted position of the plasma wake of Venus, suggesting that the ions were of Venusian arigin. Furthermore, the observed ion energy distributions yielded a "cool" temperanure of $5600 \mathrm{~K} / \mathrm{amu}$, which implied to Gunwaldt et al. (1997) that the ions originate in the "cool" ionosphere of Venus and are not the "hot" pickup jons formed in the corona of the planet. This result was made clear when they showed that their observed intersteller pickup $\mathrm{He}^{+}$lux distributions had a much wider energy width than those of $\mathrm{O}^{+}$and $\mathrm{C}^{+}$.

\section{PICKUP IONS}

The energy distributions of pickup jons have been measured at Titan and Venus. We consider those measured at Venus first because a fraction of the observations were made in the source region. Flux distributions of pickup $\mathrm{O}^{+}$and ambient, stocked solar wind $\mathrm{H}^{+}$observed by the OPA in the ionosheath above the dayside ionopause are shown in Figure 5. The $\mathrm{O}^{+}$flux was measured as a function of ion energies per unit charge, but is plotted bere as a function of equivalent proton speeds. This example typifies the structure of the flux distributions in the dayside ionosheath source region. In this example, the $\mathrm{H}^{+}$bulk speeds are about $70 \mathrm{~km} \mathrm{~s} \mathrm{~s}^{-1}$ and the corresponding peak speed for $\mathrm{O}^{+}$is about $190 \mathrm{~km} \mathrm{~s}^{-1}$. Although a range of peak speeds have been observed by the OPA in the $\mathrm{O}^{+}$source region, none have been identified to have equivalent speeds anywhere near 8 times the bulk speed of the ambient $\mathrm{H}^{+}$plasma (this of course does not consider those cases where the peaks may exist but were not observed because they occur above the energy limit of the OPA). In many cases this is expected because the sin $\alpha$ is much less than 1. However there are a number of places where sin $\alpha$ is near 1; e.g., in the sub-solar wind meridian plare.

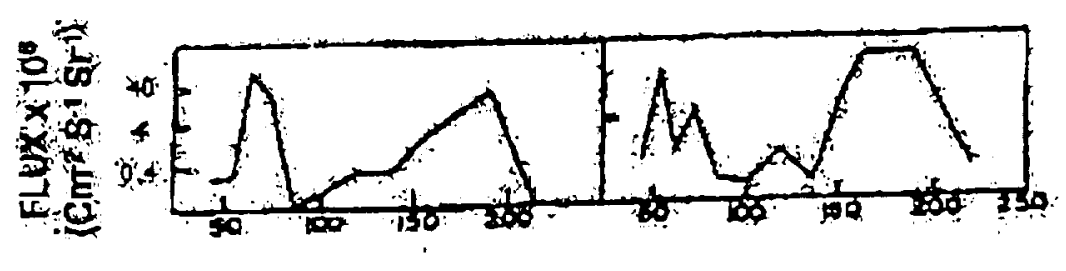

\section{PROTON SPEED KN S -}

Fig 5. $\mathrm{H}^{+}$and $\mathrm{O}^{-}$ion flux observed by OPA in the $\mathrm{O}^{+}$source region in the dayside ionosheath of Venus.

The $\mathrm{O}^{+}$peak is not expected to occur at the maximum possible energy when the $\mathrm{O}^{+}$gyroradius is large, because finite gyroradius effects become important. Pickup $\mathrm{O}^{+}$ions are born in the dayside ionosheath where the parent hot O corona extends well ajove the ionopause (Nagy et al.,1990). Electron impact, photoionization, and charge exchange form $\mathrm{O}^{+}$from $\mathrm{O}$, which is then picked up by the flowing ionosheath plasma. At altitudes between $500 \mathrm{~km}$ and $3000 \mathrm{~km}$, in those regions where the sin $\alpha>0.5$, the $\mathrm{O}^{+}$gyroradius is large, varying from about 2 to 7 times the scale height of the hot exygen. Consequently, most of the ions (an e-folding amount) at a given observation point were born about an $\mathrm{O}$ scale height upstream. Because the $\mathrm{O}^{+}$gyroradius is much larger than an $\mathrm{O}$ scale height they have only traversed part of their cycloidal trajectory and therefore the bulk of the jons bave not accelerated to their full potential by the time they reach the observation point. Jons that come from several scale beights away from the observation point certainly attain their maximum velocity, but their weight in the flux distribution is exponentially dimirished. This naturally produces a jeak flux that oceurs at energies less than the maximum possible energy. Applying this concept to the pickup $\mathrm{O}^{+}$jons observed in and gear the ionotail at PVO apoapsis, it becomes clear that $\mathrm{O}^{+}$ions born with large gyroradii should have flux peaks that do not occur at the maximum possible energies, simply because finite gyroradius effects would have distributed the ion velocities this way at birth.

At Jitan, the principal ions observed to be picked up in this moon's ion exosphere by Saturn's rotating magnetospheric plasma are $\mathrm{H}^{+}, \mathrm{N}^{+}$and/or $\mathrm{N}_{2}{ }^{+}$. As mentioned previously, abrupt flux dropouts above their cutoff or 
maximum allowed energy identified the $\mathrm{H}^{+}$pickup ions. This is valid because the ratio of the $\mathrm{H}^{+}$gyroradius to the scale height of $\mathrm{H}$ is much less than 1. On the other hand, this ratio is considerably greater than 1 for $\mathrm{N}^{+}$and $\mathrm{N}_{2}{ }^{+}$. Considering the Cytherian example above, these hcavy ions cannot be identified by their cutoff energies because finite gyroradius corrections are large. Their peak fluxes should appear well below their maximum possible energies. The flux distributions of these ions observed just outside the magnetic tail of Titan by the PSI (point 4 of Figure 4 in Hartle et al, 1982) inplied that they played a significant role in slowing down the magnetospheric plasma through mass loading. However, a quantitative understanding of this process awaits precise measurements of the complete velocity distributions.

\section{REFERENCES}

Bauer, S. J., and R. E. Hartle, Venus Ionospbere: An Interpretation of Mariner 10 Observations, Geophys. Res. LeT., $1,7 \cdot 10,1974$.

Brace, L. H., R. E. Hartle and R. F. Theis, The Nightward Ion Flow Scenerio at Venus Revisited, Adv. Space Res, 16, (6)99-(6)122, 1995.

Bridge, H. S., J. W. Belcher, A. J. Lazarus, S. Olbert, J. D. Sullivan, et al., Plasma Observations Near Sarum: Initial Results from Voyager 1, Science, 212. 217-224, 1981.

Cravens, T.E., and H. Shinagawa, The Ionopause Current Layer at Venus, J. Geophys. Res., 96, 11,119-11,113, 1991.

Grunwaldt, H., M. Neugebauer, M. Hilchenbach, P. Bochsler, D. Hovestadt, et al., Venus Tail Ray Observation near Earth, Geophys. Res. Lett., 24, 1163-1166, 1997.

Harle, R. E., and J. M. Grebowsky, Light Ion Flow in the Nightside Ionosphere of Venus, J. Geophys. Res., 98, 7437-7445, 1993.

Hartle, R. E., and J. M. Grebowsky, Planetary Loss from Light Ion Escape on Venus, Adv. Space Res, 15, (4)117(4) $122,1995$.

Hartle, R. E., T. M. Donabue, J. M. Grebowsky and H. G. Mayr, Hydrogen and Deuterium in the Thermosphere of Venus: Solar Cycle Variations and Escape, J. Geophys. Res., 101, 4525-4538, 1996.

Harle, R E., E. C. Sittler,Jr., K. W. Ogilvie, J. D. Scudder, A. J. Lazaras, and S. K. Atreya, Titan's Ion Exospbere Observed from Voyager 1, J. Geophys. Res., 87, 1383-1394, 1982.

Intriligator, D. S., Results of the First Statistical Study of Pioneer Venus Orbiter Plasma Observations in the Distant Venus Tail: Evidence for a Hemispteric Asymmetry in the Pickup of Ionospheric Ions, Geophys. Res. Lett., 16, 167-170, 1989.

Knudsen, W. P., P. M. Banks, and K I. Miller, A New Concept of Plasma Motion and Planetary Magnetic Fields. Geophys. Res. Leth, 9, 762-765, 1982.

Nagy, A. F., J. Kir, and T. E. Cravens, Hot Hydrogen and Oxygen Atoms in the Upper Atmospheres of Venus and Mars, Annales Geophysicae, 8, 251-256, 1990.

Ness, N. F., M. H. Acuna, R. P. Lepping, J. E. P. Connerney, K. W. Behannon, et al., Magnetic Field Studies by Voyager 1: Preliminary Results a: Sanurn, Science, 212, 211-217, 1981.

Slavin, J. A., D. S. Intriligator, and E. J. Smith, Pioneer Venus Orbiter Mágnetic Field and Plasma Observations in the Venus Magnetotail, J. Geophys. Res., 94, 2383-2394, 1989. 